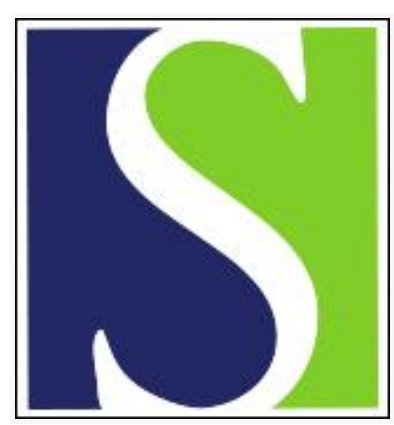

Scand J Work Environ Health 2012;38(2):105-119

https://doi.org/10.5271/sjweh.3184

Published online: 01 Aug 2011, Issue date: Mar 2012

Occupational health and safety among commercial sex workers

by Ross MW, Crisp BR, Månsson S-A, Hawkes S

Affiliation: Center for Health Promotion and Prevention Research, School of Public Health, University of Texas, PO Box 20036, Houston

TX 77225, USA. Michael.W.Ross@uth.tmc.edu

Key terms: occupational health; occupational health and safety; $\mathrm{OHS}$;

$\mathrm{OSH}$; prostitution; safety; sex; sex work; sex worker

This article in PubMed: www.ncbi.nlm.nih.gov/pubmed/21808944 


\title{
Occupational health and safety among commercial sex workers
}

\author{
By Michael W Ross, PhD, MedDr, MPH, ${ }^{1,2}$ Beth R Crisp, PhD, ${ }^{3}$ Sven-Axel Månsson, PhD, ${ }^{2}$ Sarah Hawkes, \\ $M B, B S, P h D^{4}$
}

\begin{abstract}
Ross MW, Crisp BR, Månsson S-A, Hawkes S. Occupational health and safety among commercial sex workers. Scand J Work Environ Health. 2012;38(2):105-119. doi:10.5271/sjweh.3184

The concept of occupational health and safety (OHS) for commercial sex workers has rarely been investigated, perhaps because of the often informal nature of the workplace, the associated stigma, and the frequently illegal nature of the activity. We reviewed the literature on health, occupational risks, and safety among commercial sex workers. Cultural and local variations and commonalities were identified. Dimensions of OHS that emerged included legal and policing risks, risks associated with particular business settings such as streets and brothels, violence from clients, mental health risks and protective factors, alcohol and drug use, repetitive strain injuries, sexually transmissible infections, risks associated with particular classes of clients, issues associated with male and transgender commercial sex workers, and issues of risk reduction that in many cases are associated with lack of agency or control, stigma, and legal barriers. We further discuss the impact and potential of OHS interventions for commercial sex workers. The OHS of commercial sex workers covers a range of domains, some potentially modifiable by OHS programs and workplace safety interventions targeted at this population. We argue that commercial sex work should be considered as an occupation overdue for interventions to reduce workplace risks and enhance worker safety.
\end{abstract}

Key terms occupational health; OHS; OSH; prostitution; safety; sex work.

Prostitution (commercial sex work) is regarded as "the oldest profession". It must also be one of the few longstanding "professions" (if profession is defined generally as a vocation or business, but not in the stricter sense as involving specialized learning, knowledge, skills, and ethics) that has its occupational health and safety (OHS) needs largely ignored. The United Nations defines sex work as "the exchange of money or goods for sexual services, either regularly or occasionally, involving female, male, and transgender adults, young people and children where the sex worker may or may not consciously define such activity as income-generating." (1). The term covers a broad range of transactions and the context in which these transactions occur has implications for accessing those at risk. While some may freely choose sex work as their occupation, others are coerced through violence, trafficking, and debt-bondage.

The OHS of commercial sex workers has until recently been a victim of moral discourses that ignore, devalue, or condemn commercial sex workers or attempt to control health for the benefit of the client rather than the sex worker. OHS issues may also be influenced by competing views that commercial sex work is abuse based in poverty and powerlessness, on the one extreme, or that it is a free occupational choice, on the other, with cultural and social context frequently being ignored (2). Sex work may be more common among women and girls but is not limited by sex or gender. Thus, the United Nations estimates that the number of boys and men involved in sex work is growing (1), and promoting the health of sex workers means recognizing the heterogeneity of the people involved in the sex industry.

\section{Methods}

This review (i) describes OHS issues among commercial sex workers from legal, personal, client, environment, and infectious disease perspectives and across cultural settings, (ii) identifies some of these needs in different situations and cultural contexts, and (iii) discusses health

1 Center for Health Promotion and Prevention Research, School of Public Health, University of Texas, Houston TX, USA.

2 Faculty of Health and Society, Malmö University, Malmö, Sweden.

3 School of Health and Social Development, Deakin University, Geelong, Australia.

${ }^{4}$ Center for International Health and Development, University College London, London, UK.

Correspondence to: Prof. Michael Ross, Center for Health Promotion and Prevention Research, School of Public Health, University of Texas, PO Box 20036, Houston TX 77225, USA. [E-mail: Michael.W.Ross@uth.tmc.edu] 
promotion for sex workers. Although we carried out an Ovid medline search for the terms "sex work" and "prostitution", and "occupational health" and "safety" for papers from 1950 to the end of 2010, only 29 references were retrieved. The authors were aware of many tangential references to OHS issues in sex work in the context of other papers. Given that an OHS approach is relatively new to the field of sex work, our review extended beyond the published literature addressing the question more broadly. We subsequently expanded the search to just the terms "sex work" and "prostitution" and reviewed the abstracts (and then the entire paper if it appeared that it might be relevant) for references to risks associated with sex work. We also reviewed the references in these papers to identify papers that were referenced but not elicited in the computer database searches and again examined abstracts and, where appropriate, the entire reference. Because the terms "occupational health" and "safety" were not frequently used in papers, although the concepts of health and risk were often identified, the latter stage of the search involved a degree of subjective judgment of relevance on the part of the authors. Those studies which provided extensive relevant material were described in detail, whereas papers in which there were brief or passing references that validated other reports but did not provide extensive material were more briefly noted.

\section{Results}

While Lorway et al (2) noted some cross-cultural commonalities in sex work, we need to discuss critically the cross-cultural issues that are involved in our review of sex work. Essentially, there are both emic (from the perspective of the sex worker) and etic (from the perspective of the researcher or observer) data and local and general perspectives. The general perspective notes the preponderance of issues such as stigma, disadvantage, and poor resource access. The local perspective (almost all the studies identified were local rather than cross-culturally comparative) identifies specific actors, attitudes, practices, barriers to safety and health, and resources. The limitations of this approach are the non-generalizability of some findings that may identify locale-specific health and safety risks. On the other hand, most studies also contain elements that are, to a greater or lesser extent, identifiable across cultures and settings, while colored by local factors. Linguistically, we use the term "commercial sex worker" as a neutral term that emphasizes the occupational and remunerated aspects of this work. Across cultures, however, a significant number of the terms used for commercial sex workers have a pejorative and often stigmatizing or dehumanizing connotation.
In a comment in The Lancet, Groneberg and colleagues (3) included the following occupational hazards that need to be taken into account in the lives of commercial sex workers: violence, harassment, infections, bladder problems, stress, depression, alcohol or drug addiction, latex allergy, and death. They noted OHS regulations as extremely important as harm-reduction strategies. Alexander (4) added musculoskeletal injuries to this list. Other occupational hazards include having money stolen by clients and being forced to have unprotected sex (5) and, for females, pregnancy (6). In their 2003 study from nine countries on five continents, Farley et al (7) found that prostitution was multi-traumatic and that close to $70 \%$ of the women surveyed about their current and lifetime history of sexual and physical violence met the criteria for post-traumatic stress disorder (PTSD). Regulations or policies which promote the health and well-being of commercial sex workers often do so as a by-product of efforts to protect the wider community or sectors of it by preventing the transmission of sexually transmitted infections (STI) through contact with commercial sex workers (8). The absence of such regulations, or indeed policies regarding the health and safety of sex workers, may largely arise from legal, moral, and religion-based stigma, along with a perception that most sex work involves females and an associated gender-based devaluation of the health and occupational needs of women.

Failure to recognize the health and safety needs of commercial sex workers signifies that prostitution is not regarded as a legitimate occupation despite the substantial size of the workforce. A decade ago, it was estimated that there were at least 8000 sex workers in New Zealand (5), a country that then had a population of around four million people. Dandona et al (9) cite a National AIDS Control Organization of India figure of $1 \%$ of Indian women involved in selling sex, and Elmore-Meegan et al (10) give a figure of $6.9 \%$ of women in Kenya who had exchanged sex for money in 1999. As it is clearly not the lack of persons involved that fails to render prostitution as being regarded as a legitimate occupation, another possibility is that the nature of the activity is not considered to be work in that being sexually active is considered a normal facet of adult life (11). A further issue in respect of whether commercial sex work is considered an occupation and therefore one in which OHS issues must be addressed concerns the nature of the workplace. While a registered brothel may be regarded as a legitimate workplace, many commercial sex workers work alone at home or in ad hoc settings, such as outdoor venues or hotel rooms rented by the hour or day, which are not universally regarded as being a workplace and thus not accorded the protections usually found in workplaces (8). However, in much modern OHS legislation, the home and external job sites are equally considered "workplaces" for safety purposes. 
Historically, among single women in many countries, those who were from poor or working class backgrounds were far more likely to be regarded as engaging in commercial sex work than those from wealthier backgrounds if they were sexually active or perceived as being so, irrespective of whether the sex was accompanied by any commercial transaction $(12,13)$. In this context, one of the key strategies to promote the health and welfare of those deemed to be engaging in commercial sex work has been some form of rescuing, even incarceration of women so as to "protect" them either from their own supposed inclinations towards immorality or the immoral actions of others (14). However while such actions may make a difference to a few individuals, they are unlikely to make a substantial and sustainable impact on the health of commercial sex workers (15).

\section{Legal hazards}

The overarching factor that affects the health of individuals involved in sex work and barter, according to Alexander (4), is the legal context in which such exchanges occur. There are numerous legal barriers to prostitution including soliciting, engaging in, or agreeing to engage in prostitution; loitering with intent to commit prostitution; living off the earnings of prostitution; encouraging or promoting prostitution; crossing state lines for the purposes of prostitution; and operating or managing a prostitution business or renting premises for that purpose (4). Male/transgender sex work is particularly compromised in some settings due to the illegality of same sex partnerships in many countries. Thus, reform of sex work laws is necessary, but insufficient if same sex relationships remain illegal. In 1999, Sweden made it illegal to purchase sex, while selling sex continued to be legal. Prostitution was officially redefined from something women were blamed for, to something that has to do with gender inequality and the personal responsibility of the clients. Sweden's prohibition of the buying of sexual services, followed by Norway and Iceland in 2009 was an important manifestation of this shift in the definition of prostitution in the Nordic context.

Fear of arrest can have a number of health consequences: chief among these is trying to reduce visibility vis à vis the police; as a consequence, street prostitutes reduce the amount of time they spend negotiating on the street before getting into a client's car and thus agree to carry out sex acts that are higher risk. Quick decisions may also make it harder to screen out potentially violent clients. In some cases, sex workers will not carry condoms that may provide evidence of their occupation, and some report that police may take their condoms during raids on premises. In extreme cases, Alexander (4) notes, police may enter brothels and rape some or all of the women, or exact sexual services for the purposes of "protection". At a wider level, for non-citizens, association with sex work may involve deportation or removal of their children from their care.

Legal sanctions make it far less likely that sex workers who have been subject to violence will go to the police, either because they believe that the police will not take their complaints seriously, or because they may be arrested themselves. The consequence of this illegality is a charter for the promotion of violence against sex workers and for substandard conditions and workplaces.

One of the few studies to examine the impact of political, legal, and police action against brothels was carried out by Jenkins \& Rahman in Bangladesh (16). They found that the consequence of forced brothel closures had several health and safety ramifications. The number of sex workers dropped and the average number of clients per woman rose; while safety - in terms of violence and unprotected sex - did not change. The number of regular clients dropped from about half to a quarter. Forced sex by police or the enforcers of local politicians rose very significantly by a factor of 7 and 3 , respectively. There was a highly significant increase in the proportion of anal sex reported, from $25 \%$ to $39 \%$. However, treatment-seeking behavior for STI rose while the time that women waited for treatment halved. Thus Jenkins \& Rahman (16) argue that legal or police harassment of brothels and sex workers may, rather than securing the health of the public, have negative as well as positive effects.

\section{Female sex workers and industry variation}

For female sex workers, the level of occupational hazards is closely tied to the level of power. Indeed, for female sex workers, lack of power is the basis of lack of choice and level of risk (11). Power for female sex workers is primarily reflected in the economics of the situation, with low pay associated with setting (street work) and high pay associated with "escorts" who may work out of their own premises or by referral and have greater choice of, and ability to screen, clients. Poorer women are more vulnerable and less able to negotiate safe sex (11). According to an East African study (17), such a disadvantaged background and little or no access to resources lead to women gravitating toward sex work in the first place. Occupational health issues in sex work for women also tend to be venue-based, with street workers having the highest risk, brothel workers an intermediate risk, and escort workers the lowest risk. However, there is a close association here between power and venue, and some cross-cultural research suggests that sex work in- as well as outdoors also psychologically harms women (18).

In a study of women who sell sex in a Ugandan trading town, Gysels et al (17) studied 34 female sex 
workers, classing them into three groups. First, there are those who operate from back-street bars (where sex is cheap and local men pay for casual sexual encounters). For this group of women, commercial sex work offered the only means to an income, often after the breakdown of a marriage. Second are waitresses in bars along the main road, who serve beer and supplement their income with truck drivers and travelers, usually using "middlemen" to arrange the interaction, and who charge an intermediate amount of money and not only earn a living but enjoy their job. Third, are women who own more up-market bars and are relatively well-off. These women have financial independence from men, charge high amounts for sex, and can negotiate good deals financially and in terms of safe sex. Diary data from this study showed that women in all three classes had a mixture of regular and casual partners but that as control and price rose, so did proportion of condom use. However, the data also indicated that regular partners did not use condoms, and that "regular" could imply anything from a few episodes of sex to frequent and longstanding relationships where the man provides regular material support in fairly explicit exchange for sexual and domestic services.

In a study in Australia, Seib et al $(19,20)$ interviewed nearly 250 female sex workers in Queensland, where private sex work has been legal since 1992 and brothels since 1999. However, there is also an unlicensed (illegal) sector (street-based sex workers and unlicensed brothels with two or more sex workers operating together). Thus, the level of organization is somewhat different from the Ugandan one, but there appears to be some equivalence in the illegal Australian sector being similar to the lowest Ugandan level, with brothel workers being close to the waitresses in the Ugandan sample.

In the Australian data, occupational risks were very unevenly distributed with over half of the illegal sex workers reporting being raped or subject to physical violence by clients in the past year, compared with only $3 \%$ of brothel-based and $15 \%$ of private sex workers. Illegal sex workers were also more likely to report being offered extra money to not use a condom (half the time, compared with $18 \%$ of private and $8 \%$ of brothel-based workers). Mental health followed the same pattern, with illegal workers reporting worse mental health (four times as likely to have poor mental health scores) than the other two legal groups; there was no difference with regard to physical health. Adjustment for "unhealthy worker" effects (previous sexual abuse, injecting drug use) reduced the association, as did negative experiences in the workplace (assault, rape, being offered extra money for unsafe sex). These analyses suggest that the poorer mental health of street-based and other illegal female sex workers is a function of both previous negative experiences and current, including drug-use and workplace-related, ones. As Seib et al (20) observed, street-based sex work is often embedded within a context of "disadvantage" (eg, violence, childhood abuse, injecting drug use, leaving home early), which is associated with engagement in sex work and subsequent risk behavior.

STI rates were compared by Seib et al (19), who examined the three groups of sex workers and a smaller sample of clients. Overall, the study population of sex workers and their clients (although this was not a random sample) reported higher lifetime rates of STI than a representative sample of the general population, with the street workers reporting a higher incidence of gonorrhea in the past two years and a quarter of all sex workers being diagnosed with chlamydia in their lifetime (and a quarter of these in the past two years). However, other work with female sex workers in Australia (21) has suggested that sex workers are much more likely to acquire STI from private (non-commercial) relationships, and it is known that female sex workers who use condoms for commercial transactions do not do so for private ones.

Segmentation of the industry, however, accounts for most of the variance in risk and safety. Plumridge \& Abel (5) studied female sex workers in a major city in New Zealand and noted the strong differences in sex worker characteristics between the legal (licensed premises) and unlicensed (street) domains. Being unlicensed is an offence (ie, illegal) under the New Zealand Prostitution Reform Act of 2003. Street workers were younger, over two thirds had started sex work when aged under 18 years, and 38\% (cf 7\% for indoor workers) cited the need for money for drugs as a reason for sex work. Looking at movement between sectors, they found that $<4 \%$ of indoor workers had started on the streets; of the "escort" workers, over half had started as escorts, and $80 \%$ of brothel workers had started their sex work careers as brothel workers. This stability of level in the industry suggests that segmentation, with all its social ramifications for clients and risk, is a major organizational determinant of risk. It also suggests that within the industry, networks may not be closely linked across levels.

\section{Violence}

Along with STI, violence is one of the most pervasive occupational hazards for sex workers and is a global phenomenon. Studies in all regions of the world have reported on the high prevalence of violence suffered by people selling sex $(10,22,23,24)$. It appears to be closely related to context, with isolated workers or workers in public places being most at risk. Bletzer (25) published an excellent anthropological analysis of violence directed toward sex workers focusing on female sex workers catering largely to farm-workers in 
rural areas in Florida. He notes that risks may not necessarily be associated with clients, as female sex workers are believed to carry large amounts of money, or drugs, and may be targeted for robbery. Female sex workers reported frank violence associated with vehicle pickups, with guns and knives (and occasionally crowbars and baseball bats) being used for coercion. The assaults ranged from rape, often including sexual acts - that the woman would not ordinarily want to perform - for no payment, to actual assault with threat of death such as strangulation, cutting, or stabbing. Violence may also involve abduction, with the sex worker taken to an unfamiliar or isolated place and often abandoned there. Bletzer notes that there are two types of violence: physical violence and the violence of not paying for services (theft). He also notes that women were more likely to report to the authorities a rape that took place in their home or a public place than an isolated area. Other forms of non-consensual activities that may occur under threat or actual violence include negotiation and payment of the price, the nature of the sex act, and the place of the "finishing moment", the latter of which is central to risk in mobile work. These reports are biased in that they come from women who survived: there are occasional reports in the press of mass murders involving female sex workers, many of whom are street workers who use drugs and may not be reported as missing.

In Bletzer's (25) sample, strategies to reduce risk included working in twos, having a male "backup" who would follow at a discreet distance, sharing information on vehicles or sites of risk, accepting only trusted referrals, or refraining from vehicle transactions, which appeared to be the most risky. On the other hand, Bletzer also notes violence arising from women robbing clients. While Bletzer reports predominantly on the risk of violence from clients, other studies have served to highlight the levels of violence that sex workers suffer at the hands of other perpetrators such as the police (26); long-term and regular partners (27); and neighbors and community members (26).

\section{Mental health}

Mental health issues vary considerably among female sex workers. Farley et al (7) found that PTSD among sex workers in South Africa, Thailand, Turkey, the US, and Zambia was present in two thirds of the sample, and did not differ by country. In an update five years later in nine countries (Canada, Colombia, Germany, Mexico, South Africa, Thailand, Turkey, the US, and Zambia), they found that close to $70 \%$ of the women met criteria for PTSD. While Farley et al concluded that prostitution is intrinsically traumatizing and the harm of prostitution is not culture-bound, Vanwesenbeeck (28) argued that it is the high prevalence of specific victimizing experi- ences, homelessness, and drug abuse that generate the PTSD. In Vanwesenbeeck's classic study (29) of Dutch commercial sex worker's well-being and risk, she found that sex workers fell into three groups. About a quarter felt and acted like professionals, managed quite well as sex workers, and had better health than a non-sex worker control group. Another quarter suffered from considerable strain and had a negative attitude toward their profession and poor physical and psychological health. The remaining half fell midway between these groups, with somewhat worse health compared with the controls but a more professional attitude. Studying burnout among female sex workers, Vanwesenbeeck (28) found that only the depersonalization score of burnout distinguished female sex workers from controls. Over $40 \%$ of the variance in depersonalization was accounted for by not working by choice, stigma, experiences of violence, and lack of control in client interactions. These data suggest that agency and context rather than sex work as such are the major contributors to poor mental health. In a study interviewing women who were exiting the sex industry in Sweden, Månsson \& Hedin (30) developed and expanded Vanwesenbeeck's concept of the "Matthew effect" (which she borrows from Robert Merton, in turn derived from St. Matthew's gospel). The "Matthew effect" refers to mental health among commercial sex workers and the impact of sexual trauma in childhood. That is, those with childhood sexual trauma do poorly, while those who have good mental health do very well. Månsson \& Hedin concluded that those who have resources in sex work do better than those who have a deficit in coping skills and mental health, with the latter ending up in an even worse situation. Those with positive social relations and institutions in their environment are in a more powerful situation (30) and this is reflected in their mental health.

\section{Alcohol and drug use}

Alcohol and drug use are frequently associated with sex work, either because the nature of the work leads to self-medication or because sex work is a relatively easy way to obtain money to finance a drug habit. However, the specific context of sex work may also require sex workers to consume alcohol. In a classic study, Fernández-Esquer (31) studied cantineras, Latinas working in lower-class bars (cantinas) in north and central America who earn a sales commission from every beer they drink. The drinking is obligatory and paid for by men who expect sexual favors in exchange. Alcohol consumption of a cantinera on a "normal" work day may be up to 11 beers. In this case, the alcohol use is an integral part of the work and not a precursor or consequence and as such, an OHS issue. Similar concerns may pertain to other sex workers in bars where they also work as 
waitresses and are expected to encourage alcohol consumption by patrons and potential clients. The health consequences of high and consistent alcohol consumption, apart from the immediate safety issues for unsafe sex and poor judgment in selection of clients who may be abusive, may include in the long-term liver disease, gastrointestinal cancers, heart disease, obesity, neuropsychiatric impairment, and pancreatitis among others.

\section{Immigration}

Immigration status may convey risk to sex workers as a disempowering status. For example, persons considered to have benefitted either directly or indirectly from the proceeds of prostitution within the past 10 years are barred from visiting the USA according to the restrictions specified in the Immigration and Nationality Act. Importantly, such restrictions include commercial sex workers who have worked in countries where prostitution is not illegal (32). There is an assumption that sex workers who are migrants are at higher risk, although this may be confounding immigration status with women who are lured or sold across national borders specifically for the purposes of what is close to sexual slavery. Data on risk for sex worker immigrants, however, do not necessarily confirm that it is the immigration status as such which conveys risk. Bautista et al (33) studied immigrant and non-immigrant female sex workers in Argentina and found that syphilis and hepatitis $C$ were higher among the Argentinean sex workers, whereas hepatitis B prevalence was higher among the migrant female sex workers. Regression analysis indicated that the migrant female sex workers were distinguished by being single, with no occupation, low-paid bar and cabaret workers who were more likely to engage in anal sex. In a major Catalan study of over 350 immigrant female sex workers from Eastern Europe, South America and Africa, Folch et al (34) found that younger age and unprotected sex were associated with prevalence of gonorrhea and chlamydia. They note that over $70 \%$ of female sex workers in Spain are now immigrants and that precarious legal ( $70 \%$ were illegal immigrants), working, and family situation and poor access to social services may make these women more vulnerable to STI. However, they found that the prevalence of STI among the migrant female sex workers was lower than in other European countries and that rates of chlamydia and gonorrhea were consistent with those among sexually active young people in Catalonia. None of the women were injecting drug users, which may also account for the low health problems and HIV rate, although there was no direct comparison with non-immigrant female sex workers. In a study of HIV risk behavior among clients of female sex workers in the Netherlands, de Graaf et al (35) found no difference in protective behavior among clients of migrant versus non-migrant female sex workers.

\section{Repetitive strain injury and other trauma}

Sexual acts may cause repetitive strain injury (RSI) if repeatedly performed. There is no formal research on trauma and RSI among sex workers of which we are aware. However, based on largely informal discussions with sex workers over more than two decades, Alexander (4) lists musculoskeletal injuries to the wrist, arm, and shoulder due to repeated "hand jobs"; jaw pain as a result of repeated fellatio; knee pain from working in a crouched position; foot problems relating to standing or walking in high heels; and back problems related to dancing or walking in high heels, or working on inadequate massage tables or beds. The specific conditions that Alexander (4) may be referring to are carpal tunnel syndrome (wrist), epicondylitis (elbow), rotator cuff syndrome (shoulder), and bursitis (knee). These would be considered Type 1 RSI as described by the UK National Health Service.

The extent to which the women have access to regular medical check-ups beyond STI testing is relevant here, because the Type 1 RSI require a diagnosis by a physician. Otherwise, their pains would be classified as Type 2 RSI (ie, non-specific pain). The jaw pain referred to by Alexander (4) is probably temporomandibular joint dysfunction (ie, dysfunction of the joints connecting the jaw with the skull on each side of the head). Problems in these joints usually arise from habitually clenching one's teeth. In the case of repeated fellatio, the strain would be caused by the repetitious motion with the jaw open.

Conditions that may arise from walking and standing on high heels would be related either to continuous load on the forefoot, causing the natural bony "arch" in the forefoot to collapse (gradually over time) that will eventually lead to pressure on tendons and/or peripheral nerves that pass under the arch, or to strain muscles in the foot. Low-back pain, usually muscular pain, can arise from leaning forward for extended periods of time, as when giving massage on too low tables or beds.

Repeated consecutive vaginal intercourse may also cause trauma. Bletzer (25) further notes vaginal trauma among women who visit labor camps where one woman will consecutively service 10-15 men per visit. Inadequate or lack of lubrication would have a similar effect. The trauma from repeated anal intercourse would be similar.

\section{Sexually transmissible infections}

STI are among the most classic occupational risks of sex workers. They are, however, determined largely by (i) sexual risk behaviors (particularly condom use); (ii) health-seeking behaviors, including screening; (iii) client characteristics; (iv) the risk levels of other (noncommercial) partners; and (v) underlying power dynamics, including socioeconomic status. Legal climate has 
a major impact on all these risks: Loff et al (36) noted that in one Australian study, the prevalence of sexually transmitted bacterial infections was 80 times greater among 63 illegal street workers than 753 of their legal counterparts, who are screened monthly.

Fang et al (37) examined the role of socioeconomic status in a sample of over 450 female sex workers in a semi-rural county in Guangxi, in southeast China, working in 85 establishments - restaurants/bars, hair salons, hair-washing rooms, or massage parlors - and in three locales: the county capital, an industrial development zone, and a rural township. Fang et al found that amount of sexual risk behavior (only $15 \%$ always used condoms with clients, but mean number of clients per week was only two) as measured by a multiple risk index implicated location as most significantly associated with sexual risk, with the urban female sex workers engaging in higher risk than their rural counterparts, and with ethnicity (Han or Zhuang Chinese) also being significant. Socioeconomic status was not, however, a significant component of the model. They suggested, at least for locale-based female sex workers in south Asia, that locale may be a primary determinant of risk.

Power differentials may be partially measured by sexual coercion. In a parallel analysis of these female sex workers in Guangxi province, Wang et al (38) reported that over $15 \%$ had experienced sexual coercion in the past six months (these female sex workers had been engaged in sex work for a mean of only one year). Nearly half $(41 \%)$ of the women who had experienced sexual coercion by clients reported using alcohol before having sex with their clients, and a third had a history of self-reported STI and a significantly higher HIV composite risk score. Interestingly, those who had been coerced reported a significantly higher level of STI/ HIV knowledge. They were more likely to have high numbers of clients and businessmen from other places as clients. There were also mental health consequences, with prevalence of suicidal thoughts and attempts in the last six months being $14 \%$ for those coerced and $8 \%$ for those not coerced.

In Tel-Aviv, a study of brothel-based female sex workers $(90 \%$ of whom were from the former Soviet Union) showed high prevalence $(9 \%)$ of pharyngeal gonorrhea (39). While vaginal condom use was almost universal, only two thirds of female sex workers practiced condom use with oral sex, and the result was an epidemic of gonorrhea arising from oral sex. The fact that HIV is rarely transmitted by oral sex appears to have been inaccurately generalized to bacterial STI (39).

Some health-related practices may actually increase risk of infection. Wang et al (40) examined the relationships between vaginal douching, STI and condom use among Chinese female sex workers and found that vaginal douching was associated with a doubled history of STI infection. There was a strong association between decreased condom use and douching, and over a third of women believed that douching could help prevent STI. However, reviews of the impact of douching on health show the practice to be highly associated with pelvic inflammatory disease (PID) and significantly but less so with ectopic pregnancy and other adverse outcomes including bacterial vaginosis, chlamydia infection, cervical cancer, and higher rates of HIV transmission $(40,41)$ although data on condom use and douching are contradictory in direction across studies.

\section{Client characteristics}

It is axiomatic that a significant amount of risk for sex workers will come from clients - violence and STI being the two main categories. Indeed, many STI will come from clients, although Lee et al (21) have noted that regular partners of female sex workers may also place them at high risk. Legal issues impact clients as much as sex workers. Studying Tajik male migrant workers in Moscow, where most are undocumented and have no legal rights or access to healthcare, Weine et al (42) noted extremely high risk behavior driven by fear of the police where migrants may bring one or two women to have sex with 10-15 men on one occasion, since it is cheaper that way and there is less chance of being caught by authorities. Vodka figures largely in such encounters and condoms do not. In addition to believing that sex with condoms is not "real sex", many of these men believe that HIV/AIDS is a problem only in Africa, do not know of its high prevalence among sex workers in Moscow, or believe that HIV does not infect Muslims. The sites of sex, workers' living spaces, may themselves be in unsafe conditions on construction sites, warehouses, or temporary habitations in parks. The parallels in the practice of taking one or two sex workers back to the dormitories of illegal workers where many men may have sex with them in a short time is strikingly parallel with the findings of Bletzer (25) on migrant workers, many of whom are undocumented, in Florida.

O'Connell Davidson (43) criticizes what she calls the discourse about prostitution as a form of sexual therapy or healing. She argues that presenting the prostitute as a kind-hearted comforter permits the client to tell himself that it is not simply lust but rather his loneliness that makes him seek out prostitutes. "But behind such narratives there are generally sexual scripts which have as much to do with vengeance and control as those enacted by any other client", says O'Connell Davidson (p152, 43). In accordance with this, Månsson (44) who has conducted in-depth interviews with Swedish clients found that, as the client sees it, it is the duty of the prostitute to make him feel potent and support his sense of being in control. The client simply transfers his urge for potency onto her. 
This is one of the keys to his vulnerability, but also his potential dangerousness. Transferring the opportunity to become potent (and sexually released) onto the prostitute, also means that the client projects his possible impotence on her. Simultaneously, in this situation, also lies the power of the woman; she possesses the opportunity to reject him and thereby to shut him out, not only from the sexual act, but also, in a deeper sense, from experiencing himself as potent and feeling alive. It is she who, so to speak, rules over life and death. That is a dangerous position of power. And the client cannot always realize or admit to himself that the impotence lies with him. In such situations, there is a fine line between sexual inadequacy and violence. The client may seek revenge because in his mind she refuses him his right to potency. "Shutting him out" this way may very well end in her being violated or even killed. The mental and physical violence which sometimes come to the surface in prostitution clearly demonstrates this $(43,44)$.

\section{Male sex workers}

Prior to the $20^{\text {th }}$ century, discourses on prostitution focused almost entirely on female sex workers. Commercial sexual contact between men was usually not recognized as prostitution but rather as unnatural or inappropriate behavior (8). Since gaining recognition, male sex work has tended to be viewed from a perspective where the male sex worker was a "deficit figure" who was likely to have been raised in a poor family environment, alcohol or drug-dependent, hostile and aggressive, incapable of forming relationships, and transient (8). Recent research, however, has demonstrated that this perception was due to highly moralistic research frameworks and samples biased toward criminal or psychiatric settings.

Clatts et al (45), in their study of heroin-using male sex workers in Hanoi, Vietnam, noted that meanings for same-sex exchange may be different from western cultures. Such meanings may not be economic or "cost-benefit" based and may include opportunities for contact with someone from a different culture, a chance to practice language skills, or based on the expectation not of immediate payment but rather deferred material rewards. Multiple types of such interests may co-exist. Thus, the concept of "sex work" may vary culturally and involve much more than an expectation of immediate payment as tends to be the expectation in western cultures. Nor does sex work always carry a sense of choice that is implied in some western settings: Lorway et al (2) note that the practice may be enforced by poverty, homelessness, hunger, and powerlessness.

Scott et al (46) note that violence associated with male sex workers tends to be associated with setting and client characteristics more than with the male sex worker. Variables that tend to be associated with vio- lence against sex workers include sex role (masculine or feminine), and the services offered: the degree to which male sex workers are at risk is tempered by characteristics such as age, social class, and ethnicity. For example, Scott et al note that sex workers under the legal age of consent, migrants, and particularly undocumented migrants, may be more vulnerable to manipulation, blackmail, or threats from clients. Those working in public spaces are at significantly higher risk of violence, particularly the less organized male sex workers who may rely more on unmediated transactions (ie, not via a medium which allows for screening such as internet, telephone or a third party) and chance encounters (45). Those who work in groups are also less likely to suffer victimization than those who work alone or in isolated settings: thus, violence against male sex workers is heavily contextual.

Two diary-based studies of male sex workers in Australia (47) and Argentina (48) have established that violence against male sex workers is a rare event (3.9\% of over 2000 in Australia and only 1.7\% of more than 200 in Argentina). Regression analysis on these data established that the best predictors of violence against male sex workers were (i) public place [car, sex work premises: odds ratio (OR) 2.7]; (ii) alcohol use by client (OR 1.1), with an effect in the opposite direction for alcohol use by the sex worker (OR 0.4), (iii) when the client was in his 40s (OR 1.2), and (iv) when the client was assessed by the male sex workers as "straight" (heterosexual: OR 2.2) (8). Minichiello et al (47) reported that violent situations tended to occur more commonly with street clients, who were also more likely to tell the sex worker what they wanted (unsafe sex was requested in only $7 \%$ of encounters). They also note that given the stigmatized status of both sex workers and clients, both are reluctant to report violence for fear of public identification or because they anticipate or have experienced poor treatment by authorities. Indeed, they suggest that a factor precipitating interpersonal violence against (or by) male sex workers is the belief that it is sanctioned and will not be reacted against. Violence by male sex workers is beyond the scope of this paper.

The practice of unprotected sex is a dynamic interplay between sex workers and clients (49), with key factors including power imbalances, notions of trust, sexual pleasure, alcohol and drug use, beliefs that malewith-male sex has lower or no HIV transmission risk, and financial considerations such as additional payment for unprotected sex. On the other hand, defining an encounter as sex work may be protective: Chemnasiri et al (50) noted that male sex workers in three cities in Thailand were significantly less likely to report inconsistent condom use than men who have non-commercial sex with men. 
The concept of "sex work" among men who have sex with men may be even more blurred than among women, although this does not necessarily make it any more difficult to identify OHS issues. However, it does make it more difficult to identify what is occupational as opposed to casual behavior. This difficulty is best illustrated by Chapman (51), whose work with migrant men who have sex with men in Shenzhen, China found fluidity regarding the concepts of both sexual identity and payment for sex. As Wang \& Ross (52) indicate, the concept of sexual identity and sexual behavior is not equivalent to Western conceptions of sexual orientation. In China, tongzhi portrays sexual desires, short of the point of an identity. Citing Chou, Wang \& Ross note his analogy that if you like beef and I like pork, that doesn't mean that you call me porkman or I call you beefwoman! Tongzhi appears to be more akin to an appetite than an identity. Chapman et al's work among tongzhi migrants in Shenzhen also emphasizes the looser social bonds that exist when people are removed from their usual setting and family ties, and where relative anonymity and sexual experimentation facilitate samesex sexual behaviors. She notes that this is aided by the extensive use of the internet to meet sexual partners, thus obviating the need for potentially identifying situational partner meeting sites (51).

The blurred nature of sexual transactions for money in Shenzhen is described by Chapman (51): "Men sell sex to men who approach them but to whom they are not necessarily sexually attracted. They then use this money to buy sex from someone to whom they are sexually attracted but who is not necessarily attracted to them" (p695). These sexual exchanges are described as opportunistic, not professional. Men who bought gifts for their sex partners (whether "money boys" - men who have sex with men - or not) did not see this event as transactional. Such blurring of commercial, transactional, and non-transactional sex has implications for condom use when clients became regulars and condom use would be discontinued. Atkinson et al (53) noted that after 3-4 sexual encounters, as intimacy increases, condom use is usually discontinued. This finding is reported across culturally diverse settings including East Africa (49). Chapman (51) also noted that familiarity with or attraction to a client changes views of the necessity of condom use among the Chinese "money boys". She argues that in the blurred context, where men may or may not view themselves as sex workers and partners may or may not view themselves as clients, non-use of condoms is an occupational hazard of an interaction not being commercially identified.

The heavy cultural and informational overlay of risk contributes largely to occupational danger. In a study of male sex workers in Mombasa, Kenya, Okal et al (49) noted a widespread view that anal sex has a significantly lower (or no) transmission risk for HIV. Where over $80 \%$ of the male sex workers in Mombasa (a major tourist destination) reported that their last male client was Kenyan, such shared risk misperceptions constitute a specific health hazard. Nevertheless, even where only $35 \%$ of these Kenyan men who have sex with men knew that HIV could be transmitted by anal sex, $36 \%$ reported consistent condom use for anal sex with male clients. In this Kenyan sample of male sex workers, common elements of occupational risk also emerge: over $12 \%$ reported experiencing physical abuse in the past year, while $10 \%$ had been sexually assaulted or raped over the same period. In their qualitative interview with 36 male sex workers in Mombasa, Okal et al (49) noted that unemployment and poverty were strongly associated with later age at first sexual encounter with another male and the desire to acquire accessories such as cell phone, shoes, and clothing. Where initial penetrative sex was a result of sexual exploitation by friends, relatives, or other trusted individuals, power imbalances - as reported throughout the literature on sex work - meant that safe sex was only feasible if the perpetrator chose to use a condom. As is the case with female commercial sex workers, for male sex workers, use of condoms or unsafe sex in their initial sexual experience appears to extend to subsequent sexual partners (54).

The second almost universal risk for non-use of condoms among male sex workers is the fact that communication leading up to and during transactional sex is replete with ambiguity (55), not only about condom use but also about the complete repertoire of acts. Okal et al (49) noted this is due to two factors: (i) the use of non-verbal signals such as dress, posture, walking style, location, and other signals to communicate to potential sexual partners; and (ii) the geographical setting of the sexual encounter. Where the encounter takes place in public or semi-public areas such as parks, beaches, or disused buildings, where interruption is an ever-present hazard, the emphasis on the rapidity of the act to minimize risk of detection, harassment, or arrest usually trumps the use of extra time to negotiate or employ a condom and lubricant. In the East African setting, the extensive stigma against men who have sex with men also leads to frequent eviction and discrimination, including job loss, if homosexual activity is suspected. Such high stigma in the East African (and other) contexts leads to many men who have sex with men and male sex workers to have girlfriends, marry, and seek medical treatment in the private setting. Marriage will also have considerations for family honor, social standing, and expectations about producing heirs, independent of social status (49). In Okal et al's research (49), safety from stigma (arguably in some locations more of an immediate threat to life and safety than HIV or STI) was sometimes achieved by carefully selecting married 
men as clients because they have a social status that they would also not want to risk. Similarly, they note, male sex workers choose clients who appear to have a career and image that they also would not want to risk. Such strategies, however, are likely to be limited to a higher socioeconomic level. Okal et al (49) also noted that although only $20 \%$ of the men they interviewed who have sex with men insisted on condom use, waterbased lubricants were not available, thus necessitating the use of oil-based lubricants. This is an additional occupational safety issue not usually noted for male sex workers, and likely associated with the stigmatization of water-based lubricants as being considered a "marker" for homosexual activity.

In China, Mi et al (56) carried out face-to-face interviews with 85 male sex workers in Beijing and Quingdao City on risk behaviors, particularly for HIV infection. Condoms were used consistently for $53 \%$ of receptive and $71 \%$ of insertive anal sex; however, over a third (35\%) did not know that condoms would protect them from HIV infection. Significant predictors of regular condom use were (i) being required to use a condom by clients (OR 44); (ii) requiring clients to use one (OR 39); (iii) being $>20$ years (OR 13); (iv) knowing that condoms would protect from HIV (OR 12); (v) regretting getting involved in the sex trade (OR 7); (vi) having both male and female clients (OR 6); and (vii) having a regular sex partner (OR 5). Of the male sex workers, $14 \%$ reported having sex with both males and females. As was also reported by Infante et al (57), younger sex workers were particularly poorly informed.

The association of sex work with drug use has been as well-established for male sex workers as for female sex workers. Clatts et al (45) compared male sex workers in a sample of young heroin users in Hanoi, Vietnam, and found that the male sex workers were more likely to be migrants with unstable housing and have more exposure to other drugs [including marijuana, MDMA (ecstacy), cocaine and morphine], sexual partners who injected drugs before or during sex, concurrent male and female partners, and a history of sexual victimization. In $71 \%$ and $47 \%$ of, respectively, receptive and insertive anal encounters with clients, no condom was used; condom use appears to be lower where the sex worker and/ or the client use drugs. Where the sex worker and client use drugs, there is thus an additional occupational risk through unsafe injecting practices and acquisition of blood-borne pathogens via the injecting route. This risk may exceed the risk of acquisition of such pathogens through their sexual contact.

Most research has focused on male sex workers who serve male clients: however, the sector of the sex industry that caters to female clients is significant and it might be anticipated that many of the same risk factors might operate.

\section{Transgendered sex workers}

Transgendered commercial sex workers form a special category with regard to OHS. Although they are technically men who have sex with men, issues of stigma, sexual practices, and available health services may place them at greater risk. Such sex workers are referred to as "TTT" (travesti, transgender, and transsexual) by Infante et al (57). The vulnerability of transgendered sex workers in Mexico, they note, is compounded by the additional stigma (related to higher visibility and lower ability to "pass"), lack of social capital, and absence of specific health services and risk reduction outreach programs. Qualitative interviews with transgendered sex workers revealed occupational risks relating to physical abuse by family members, violence or rape by police and prison officers, being beaten up in the street, and generally worse violence than that experienced by male sex workers (in addition to discrimination from the gay community). Similar findings are reported by Lorway et al (2) in Mysore, India, with coerced condomless anal sex occurring at the hands of police and "rowdies" (men who extort money and "free" sex from sex workers) and by Hawkes et al (58) in Pakistan who found that over a quarter of transgender sex workers reported being raped by the police in the past year, compared with $11 \%$ of male sex workers and $8 \%$ of female sex workers reporting police rape in the same cities. However, Infante et al (57) also suggested that there may be a strong social class component to such discrimination, along with social capital and the amount of investment in appearance and physical transformation. In general, it seems that the more obviously transgendered the sex worker, the greater discrimination and abuse they will face. As with other sex workers, those working out of bars and clubs or beauty salons are protected more by their location than those selling their services on the street. The need to maintain a feminine appearance despite a male habitus adds additional risks for transgendered sex workers. Infante et al (57) note that transgendered sex workers needed to buy hormones and oils, which are frequently used incorrectly, both in terms of inappropriate dosage and administration (eg, damaging skin and muscles by injecting oil). Inappropriate injection of silicone or other substances to create or enhance breasts may also constitute a risk. Particularly important, Infante et al (57) noted the lack of availability of any governmental health service that engages in response to the health and informational needs of the transgendered sex worker population, thus compounding the risks.

Indian data on transgendered sex workers mirrors these findings. Shinde et al (59) studied 75 male sex workers attending a clinic in Mumbai, 51 of whom were transgendered. HIV prevalence was $17 \%$ among men versus $41 \%$ among transgendered sex workers. Kothis were effeminate men who could pass as hetero- 
sexual or homosexual as the situation required, while hijras (transgendered, crossdressing men who may have undergone castration or other genital surgery) did not have that option. Panthis are masculine-identified men who have sex with men. High levels of other STI were also identified, including $28 \%$ with syphilis serology (although it is unclear if this represents untreated infection), and $26 \%$ with positive herpes simplex 2 (HSV-2) serology. Two thirds reported having $2-5$ clients per night, and condom negotiation depended on economic considerations, physical and/or emotional attraction to the client, types of sexual practices (oral versus anal sex), and type of sexual partner (unskilled or skilled laborer or professional, with those with unskilled laborer clients reporting a $44 \% \mathrm{HIV}$ infection rate). These findings are mirrored in Pakistan where Hawkes et al (58) found over $48 \%$ of 269 transgender sex workers with active syphilis, $20 \%$ with rectal gonorrohoea and 10\% with rectal chlamydia - rates much higher than those found among either male or female sex workers tested for the same pathogens.

Transgendered sex workers apparently experience serious stigma and violence from clients in most cultures and societies: Harcourt et al (60) reported that this group in Sydney, Australia, also suffered disproportionately from discrimination and intolerance in the community, including a shortage of sympathetic mental health services accessible to transgendered sex workers.

\section{Occupational health promotion}

Given the lack of power inherent in many female sex workers' workplaces, health promotion for sex workers may depend on "gatekeepers" (owners and managers of sex worker establishments). Yang et al (61) found a significant role of gatekeepers in safety. They reported that perceived support of the gatekeeper was associated with condom use communication with sexual partners, condom use frequency and intention to use condoms, self-efficacy about condom use, lower barriers to condom use, and perceived peer condom use. These data make it obvious that healthcare and OHS professionals should wherever possible work with gatekeepers to create supportive workplace environments for condom use, and that gatekeepers need to articulate this support to sex workers.

Health promotion to achieve a safer workplace is crucial to implementation of safety awareness and measures to promote safety of workers. Rickard \& Growney (62) used a peer-education approach to sex workers in London, with a short (28 minute) audio cassette that involved stories from other sex workers about selected key safety issues and sex worker approaches to it, based on an oral history project. In a process evaluation, they found that the cassettes stimulated discussion of health and safety issues. These stories about different aspects of health and safety in sex work were positively rated by 15 female sex workers who commented on the practical advice and sensible suggestions relating to safety and vetting "dodgy punters". A minority of female sex workers characterized the tape as "depressing". However, the tape was also listened to by other female sex workers outside the sample, indicating the importance of peer networks in the distribution of information.

Withers et al (63) nevertheless noted that sex workers themselves may have limited agency in sexual safety and health at sex work establishments, and that sexual health policy may largely rest in the domain of manager and establishment characteristics. They cite a number of studies that indicate that focusing solely on individual factors and individual behaviors among sex workers are ineffective in developing and sustaining condom use. Structural factors, however, can increase condom use among sex workers. They surveyed 162 establishments in four different Philippino cities, covering "direct" sex work establishments (brothels) as well as "indirect" (karaoke bars, massage parlors, hotels, and bars) sites. Data indicated that older age of manager, membership in a manager association, establishment type, and number of employees were all significantly associated with promotion of condom use. A high proportion (42\%) of the variance in their sexual health policy measure could be predicted by number of employees and establishment type (karaoke bars being the least likely to promote condom use). Karaoke bars were the only establishments not included in city ordinances mandating regular female sex worker health check-ups, suggesting that city ordinances may play a significant part in promoting health and safety in this area. The work of Withers et al (63) emphasizes the importance of including the contextual and organizational aspects of sex work in any health promotion efforts.

\section{Discussion}

OHS is as central to sex work as to any other area of work. Some of the most significant barriers to health and safety among sex workers are legal issues. Where some or all aspects of sex work or sexual behaviors - such as same sex relationships - are illegal, it is almost impossible to provide basic health and safety for sex workers. Such legal barriers encourage poor workplace safety, violence, lack of screening for STI, blackmail , and extortion. Brents \& Hausback (64) argue that legalization brings a level of public scrutiny that decreases the risk of violence, and Maticka-Tyndale et al (65) note that, for exotic dancers, the stereotype of the job allows men to see the dancers as legitimate prey for sexual 
harassment and assault. However, it all depends on the context in which the transactions occur. Long-term experiences from Sweden show that in a legal context that prohibits the buying of sexual services, it is still possible to provide protection and social and health services to women and men in prostitution. Irrespective of which formal legal system is in operation, in reality most sex workers are forced to transact their services outside the protection of the law. Social stigma and discrimination create an environment that perpetuates a culture of violence. Their basic human rights are commonly disregarded and they are more often than not penalized and targets of harassment, not least from their own networks of clients, pimps, and partners. There are thus various legal options, including: decriminalization (removal of laws against prostitution and allowing the "free market" to operate); partial criminalization of clients, as in some Scandinavian countries; legalization, which may provide for regulation, licensing, and screening of sex workers and their work premises; and encouragement of condom use.

In an industry as highly segmented as sex work, with relatively minimal movement between segments, OHS issues will differ not only between segments, but also across the gender of sex workers (female, male and transgendered). Power issues are key to safety, with the least empowered workers the least able to control violence and require condom use. In the street sector, where many of the more disadvantaged workers are found, there is also likely to be a higher "unhealthy worker" component, with sex workers bringing into the job disadvantages such as drug and alcohol abuse, and mental health issues. Any approach to OHS in this group will need to take into account some of the pre-existing health, particularly mental health, conditions that workers may bring into, and be exacerbated by, the job (the "Matthew effect") (30).

Sex work involves a dynamic between the worker and the client, and it is difficult to separate these two players in any attempt to improve OHS or promotion of safe sex work encounters. Any attempt to demonize one or the other of these key players or to justify health and safety to the benefit of one or the other is not only philosophically dangerous, but likely to undermine any effective health promotion approach to this industry where worker and client risk is a dynamic interaction. Recently, Langanke \& Ross (66) reported on internet forums, where clients of female sex workers share experiences and which serve to promote sexual safety, highlighting the potential importance of the internet as a medium not only as a marketplace for sexual services, but also for health and safety information for both clients and commercial sex workers.

There is evidence that effective OHS interventions targeted at sex workers involve health promotion approaches that are generated with sex workers and their organizations and that such approaches are the most effective and accepted by workers and clients. Workplace as well as worker and client components are all crucial points of intervention and cannot be effectively implemented without legal or policy changes, as appropriate. Sometimes such changes will involve professional education with those most involved with sex work issues, such as health personnel, police, city officials, local businesses, and local STI and drug and alcohol treatment services. The final component of effective sex worker OHS is having health and outreach workers who are empathic and comfortable with the sex worker communities and who can provide services at times and places convenient to the context of sex work.

The legal and moral stigmata associated with sex work have proved major barriers to providing appropriate OHS for sex workers. In 2003, the European Agency for Health and Safety at Work (67) also noted that sex workers are often overlooked in OHS activities. One reason is that their work is often illegal and not covered by OHS or other employment regulations. While for some sex workers, there is minimal if any choice in their occupation, for others it is a rational and free decision. It is crucial that OHS among sex workers should take account of such a continuum of degree of choice without compromising the commitment to providing health and safety services for all workers in the sex industry.

\section{Acknowledgements}

An earlier version of this paper was presented at a seminar in the Centro de Investigación en Salud Laboral (CISAL), Pompeu Fabra University, Barcelona, Spain. The authors thank CISAL for its support toward its preparation and presentation. We thank Dr Eva Denison of the Norwegian Knowledge Center for the Health Sciences, Oslo, Norway, for her helpful comments on strain injuries, and Dr Maria E Fernández-Esquer, University of Texas School of Public Health, for her discussions on cross-cultural aspects of sex work.

\section{References}

1. UNAIDS Inter-Agency Task Team on Gender and HIV/ AIDS. HIV/AIDS, Gender and Sex Work. Available from: http://www.unfpa.org/hiv/docs/factsheet_genderwork.pdf. Accessed on January 3, 2011.

2. Lorway R, Reza-Paul S, Pasha A. On becoming a male sex worker in Mysore: Sexual subjectivity, "empowerment", and community-based HIV prevention research. Med Anthropol Q. 2009;23:142-160. doi:10.1111/j.1548-1387.2009.01052.x. 
3. Groneberg DA, Molliné M, Kusma B. Sex work during the world cup in Germany. Lancet. 2006;368:840-841. doi:10.1016/S0140-6736(06)69324-0.

4. Alexander P. Sex work and health: A question of safety in the workplace. J Am Med Women's Assoc. 1998;53:77-82.

5. Plumridge L, Abel G (2001). A "segmented" sex industry in New Zealand: Sexual and personal safety of female sex workers. Aust NZ J Public Health. 2001;25:78-83. doi:10.1111/j.1467-842X.2001.tb00555.x.

6. Sanders, T (2004). A continuum of risk? The management of health, physical and emotional risks by female sex workers. Sociol Health Illn. 2004;26: 557-574.doi:10.1111/j.01419889.2004.00405.x.

7. Farley M, Cotton A, Lynne J, Zumbeck, S, Spiwak, F, Reyes, ME, Alvarez D, Sezgin, U. Prostitution and trafficking in nine countries: an update on violence and posttraumatic stress disorder. J Trauma Pract. 2003;3/4:3374.

8. Scott, JG. How Modern Governments Made Prostitution a Social Problem: Creating a Responsible Prostitute Population. Lewiston, New York: Edward Mellen Press, 2005.

9. Dandona R, Dandona L, Kumar GA, Gutierrez JP, McPherson S, Samuels F, Bertozzi SM, and the ASCI FPP Study Team. Demography and sex work characteristics of female sex workers in India. BMC Int Health Hum Rights. 2006;6:5. doi:10.1186/1472-698X-6-5.

10. Elmore-Meegan M, Conroy R, Agala B. Sex workers in Kenya, numbers of clients and associated risks: an exploratory survey. Reprod Health Matters. 2004;12(23):50-57. doi:10.1016/ S0968-8080(04)23125-1.

11. Barnard MA. Violence and vulnerability: Conditions of work for streetworking prostitutes. Sociol Health Illn. 1993;15:683705. doi:10.1111/1467-9566.ep11434434.

12. Abrams LS. Guardians of virtue: The social reformers and the "girl problem", 1890-1920. Soc Serv Rev. 2000;74:436-452. doi:10.1086/516412.

13. Abrams LS, Curran, L. Wayward girls and virtuous women: social workers and female delinquency in the progressive era. Affilia. 2000;15:49-64.

14. Mahood L, Littlewood B (1994). The "vicious" girl and the "street-corner" boy: sexuality and the gendered delinquent in the Scottish child-saving movement 1850-1940. J Hist Sex. 1994;4:549-578.

15. Swerissen H, Crisp BR. (2004) The sustainability of health promotion interventions at four levels of organization. Health Promot Int. 2004;19:123-130. doi:10.1093/heapro/dah113.

16. Jenkins $\mathrm{C}$, Rahman H. Rapidly changing conditions in the brothels of Bangladesh: impact on HIV/STD. AIDS Educ Prev. 2002;14(Suppl. A):97-106. doi:10.1521/aeap.14.4.97.23882.

17. Gysels M, Pool R, Nnalusiba B. Women who sell sex in a Ugandan trading town: Life histories, survival strategies and risk. Soc Sci Med. 2002;54:179-192. doi:10.1016/S02779536(01)00027-2.

18. Farley M. Prostitution harms women even if indoors. Reply to Weitzer. Viol Ag Women. 2005;7:950-984 doi:10.1177/1077801205276987.
19. Seib C, Debattista J, Fischer J, Dunne M, Najman JM. Sexually transmissible infections among sex worker and their clients: variation in prevalence between sectors of the industry. Sex Health. 2009;6:45-50. doi:10.1071/SH08038.

20. Seib C, Fischer J, Najman JM. The health of female sex workers from three industry sectors in Queensland, Australia. Soc Sci Med. 2009;68:473-478. doi:10.1016/j. socscimed.2008.10.024.

21. Lee D, Binger A, Hocking J, Fairley C. The incidence of sexually transmitted infections among frequently screened sex workers in a decriminalized and regulated system in Melbourne. Sex Transm Infect. 2005;81:434-436. doi:10.1136/sti.2004.014431.

22. Azim T, Chowdhury EI, Reza M, Ahmed M, Uddin MT, Khan R, Ahmed G, Rahman M, Khandakar I, Khan SI, Sack DA, Strathdee SA. Vulnerability to HIV infection among sex worker and non-sex worker injecting drug users in Dhaka, Banglaedsh: evidence from the baseline survey of a cohort study. Harm Reduct J. 2006;3:33. doi:10.1186/1477-7517-3-33

23. Gilchrist G, Gruer L, Atkinson J. Comparison of drug use and psychiatric morbidity between prostitute and non-prostitute female drug users in Glasgow, Scotland. Addic Behav. 2005;30(5):1019-1023. doi:10.1016/j.addbeh.2004.09.003.

24. Silbert MH. Occupational hazards of street prostitutes. Crim Justice Behav. 1981;8(4):395-399. doi:10.1177/009385488100800401.

25. Bletzer KV. Risk and danger among women-who-prostitute in areas where farmworkers predominate. Med Anthropol Q. 2003;17:251-258. doi:10.1525/maq.2003.17.2.251.

26. Mayhew S, Collumbien M, Qureshi A, Platt L, Rafiq N, Faisel A, Lalji N, Hawkes S. Protecting the unprotected: mixed-methods research on drug use, sex work and rights in Pakistan's fight against HIV/AIDS. Sex Transm Infect. 2009;85(suppl 2):ii31-36. doi:10.1136/sti.2008.033670.

27. El-Basssel, Wiitte SS, Wada T, Gilbert L, Wallace J. Correlates of partner violence among female street-based sex workers: substance abuse, history of childhood abuse and HIV risks. AIDS Patient Care STDs. 2001;15(1):41-51. doi:10.1089/108729101460092.

28. Vanwesenbeeck I. Burnout among female indoor sex workers. Arch Sex Behav. 2005;34:627-639. doi:10.1007/s10508-0057912-y.

29. Vanwesenbeeck I. Prostitutes' well-being and risk. Amsterdam: Amsterdam University Press, 1994.

30. Månsson S-A, Hedin U-C. Breaking the Matthew effect - on women leaving prostitution. Int J Soc Welf. 1999;8:67-77. doi:10.1111/1468-2397.00063.

31. Fernández-Esquer ME. Drinking for wages: Obligatory alcohol abuse among Cantineras. J Stud Alcohol. 2003;64:160-166.

32. Williams M. Can you imagine a World AIDS conference without the red umbrellas? HIV Aust. 2010;8(3):40-41.

33. Bautista CT, Pando MA, Reynaga E, Marone R, Sateren WB, Montano SM, Sanchez JL, Avila MM. Sexual practices, drug use behaviors, and prevalence of HIV, syphilis, hepatitis B and $\mathrm{C}$, and HTLV-1/2 in immigrant and non-immigrant female sex workers in Argentina. J Immigr Minor Health. 2009;11:99- 
104. doi:10.1007/s10903-007-9114-2.

34. Folch C, Esteve A, Sanclemente C, Martró E, Lugo R, Molinos S, Gonzalez V, Ausina V, Casabona J. Prevalence of HIV, Chlamydia trachomatis, and Neisseria gonorrheae and risk factors for sexually transmitted infections among immigrant female sex workers in Catalonia, Spain. Sex Transm Dis. 2008;35:178-183. doi:10.1097/OLQ.0b013e31815a848d.

35. De Graaf R, van Zesen G., Vanwesenbeeck I, Straver CJ, Visser JH. Segmentation of heterosexual prostitution into various forms: A barrier to the potential transmission of HIV. AIDS Care. 1996;8:417-431. doi:10.1080/713613062.

36. Loff B, Gaze B, Fairley C. Prostitution, public health, and human rights law. Lancet. 2000;356:1764. doi:10.1016/ S0140-6736(00)03219-0.

37. Fang X, Li X, Yang H, Hong Y, Stanton B, Zhao R, Dong B, Liu W, Zhou Y, Liang S. Can variation in HIV/STD-related risk be explained by individual SES? Findings from female sex workers in a rural Chinese county. Health Care Women Int. 2008;29:316-335. doi:10.1080/07399330701738382.

38. Wang B, Li X, Stanton B, Fang X, Yang H, Zhao R, Hong Y (2007). Sexual coercion, HIV-related risk, and mental health among female sex workers in China. Health Care Women Int. 2007;28:745-762. doi:10.1080/07399330701465226.

39. Linhart Y, Shohat T, Amitai Z, Gefen D, Srugo I, Blumstein G, Dan M. Sexually transmitted infections among brothelbased sex workers in Tel-Aviv area, Israel: High prevalence of pharyngeal gonorrhea. Int J STD AIDS. 2008;19:656-659. doi:10.1258/ijsa.2008.008127.

40. Wang B, Li X, Stanton B, Yang H, Fang X, Zhao R, Dong B, Zhou Y, Liu W, Liang S. Vaginal douching, condom use and sexually transmitted infections among Chinese female sex workers. Sex Transm Dis. 2005;32:696-702. doi:10.1097/01. olq.0000175403.68410.ec.

41. Zhang J, Thomas AG, Leybovich E. Vaginal douching and adverse health effects: A meta-analysis. Am J Public Health. 1997;87:1207-1211. doi:10.2105/AJPH.87.7.1207.

42. Weine S, Bahromov M, Mirzoev A. Unprotected Tajik male migrant workers in Moscow at risk for HIV/AIDS. J Immigr Minor Health. 2008;10:461-468. doi:10.1007/s10903-0079103-5

43. O'Connell Davidson, J. Prostitution, Power and Freedom. Cambridge: Polity Press, 1998.

44. Månsson S-A. Sex as a commodity. On prostitution and pornography in the late modern society. In Træen, B, Lewin, B. Sexology in Context. A Scientific Anthology. Oslo: Universitetsforlaget, 2008, p193-226.

45. Clatts MC, Giang LM, Goldsamt LA, Yi H. Male sex work and HIV risk among young heroin users in Hanoi, Vietnam. Sex Health. 2007;4:261-267. doi:10.1071/SH07018.

46. Scott J, Minichiello V, Mariño R, Harvey GP, Jamieson $\mathrm{M}$, Browne J. Understanding the new context of the male sex work industry. J Interpers Violence. 2005;20:320-342. doi: $10.1177 / 0886260504270334$.

47. Minichiello V, Mariño R, Browne J, Jamieson M. A profile of the clients of male sex workers in three Australian cities. Aust
NZ J Public Health. 1999;23:511-518. doi:10.1111/j.1467842X.1999.tb01308.x.

48. Mariño R, Minichiello V, Disogra C. A profile of clients of male sex workers in Córdoba, Argentina. Int J STD AIDS. 2004;15:266-272.

49. Okal J, Luchters S, Geibel S, Chersich MF, Lango D, Temmerman M. Social context, sexual risk perceptions and stigma: HIV vulnerability among male sex workers in Mombasa, Kenya. Cult Health Sex. 2009;11: 811-826. doi:10.1080/13691050902906488.

50. Chemnasiri T, Netwong T, Visarutratana S, Varangrat A, Li A, Phanuphak P, Jommaroeng R, Akarasewi P, van Griensven F. Inconsistent condom use among young men who have sex with men, male sex workers, and transgenders in Thailand. AIDS Educ Prev. 2010;22:100-109. doi:10.1521/ aeap.2010.22.2.100

51. Chapman J, Cai Y, Hillier S, Estcourt C. Sex and sexuality in the Shenzhen tongzhi circle: HIV risk context and migrant men who have sex with men in China. Cult Health Sex. 2009;11:689-702. doi:10.1080/13691050902977562.

52. Wang Q, Ross MW. Differences between chat room and email sampling approaches in Chinese men who have sex with men. AIDS Educ Prev. 2002;14:361-366. doi:10.1521/ aeap.14.6.361.24081.

53. Atkinson JS, Williams ML, Timpson SC, Nilsson Schönnesson L. Multiple partnerships in a sample of African American crack smokers. AIDS Behav. 2010;14:48-58. doi:10.1007/s10461007-9346-0.

54. World Health Organization. Violence against women and HIV/ AIDS: Critical intersections. Violence against sex workers and HIV prevention. Geneva: WHO, 2005.

55. Bloor M, Barnard M, Finlay A, McKeganey N. HIV-related risk practices among Glasgow male prostitutes: Reframing concepts of risk behavior. Med Anthropol Q. 1993;7:152-169. doi:10.1525/maq.1993.7.2.02a00020

56. Mi G, Wu Z, Zhang B, Zhang H. Survey on HIV/AIDS-related high risk behaviors among male sex workers in two cities in China. AIDS. 2007;21(suppl. 8):S67-S72. doi:10.1097/01. aids.0000304699.85379.32.

57. Infante C, Sosa-Rubi SG, Magali Cuadra S. Sex work in Mexico: vulnerability of male. travesti, transgender and transsexual sex workers. Cult Health Sex. 2009;11:125-137. doi:10.1080/13691050802431314.

58. Hawkes S, Collumbien M, Platt L, Lalji N, Rizvi N, Andreasen A, et al. HIV and other sexually transmitted infections among men, transgenders and women selling sex in two cities in Pakistan: a cross-sectional prevalence survey. Sex Transm Infect. 2009;85: ii8-ii16. doi:10.1136/sti.2008.033910.

59. Shinde S, Setia MS, Row-Kavi A, Anand V, Jerajani H. Male sex workers: Are we ignoring a risk group in Mumbai, India? Indian J Dermatol Venereol Leprol. 2009;75:41-46. doi:10.4103/0378-6323.45219.

60. Harcourt C, van Beek I, Heslop J, McMahon M, Donovan $B$. The health and welfare needs of female and transgender sex workers in New South Wales. Aust NZ J Public Health. 2001;25:84-89. doi:10.1111/j.1467-842X.2001.tb00556.x. 
61. Yang H, Stanton B, Fang X, Zhao R, Dong B, Liu W, Liang $\mathrm{S}$, Zhao Y, Hong Y. Condom use among female sex workers in China: Role of gatekeepers. Sex Transm Dis. 2005;32:572580. doi:10.1097/01.olq.0000175418.48665.95.

62. Rickard W, Growney T. Occupational health and safety among sex workers: A pilot peer education resource. Health Educ Res. 2001;16:321-333. doi:10.1093/her/16.3.321.

63. Withers M, Dornig K, Morisky DE. Predictors of workplace sexual health policy at sex work establishments in the Philippines. AIDS Care. 2007;19:1020-1025. doi:10.1080/09540120701294229.

64. Brents BG, Hausbeck K. Violence and legalized brothel prostitution in Nevada: examining safety, risk and prostitution policy. J Interpers Violence. 2005;20:270-295. doi:10.1177/0886260504270333.
65. Maticka-Tyndale E, Lewis J, Clark JP, Zubick J, Young S. Social and cultural vulnerability to sexually transmitted infection: The work of exotic dancers. Canadian J Public Health. 1999;90:19-22.

66. Langanke H, Ross MW. Web-based forums for clients of female sex workers: development of a German internet approach to HIV/STD-related sexual safety. Int J STD AIDS. 2009;20:4-8. doi:10.1258/ijsa.2008.008202.

67. European Agency for Safety and Health at Work. Gender issues in safety and health at work: A review. Luxembourg: Office for Official Publications of the European Communities, 2003.

Received for publication: 11 January 2011 